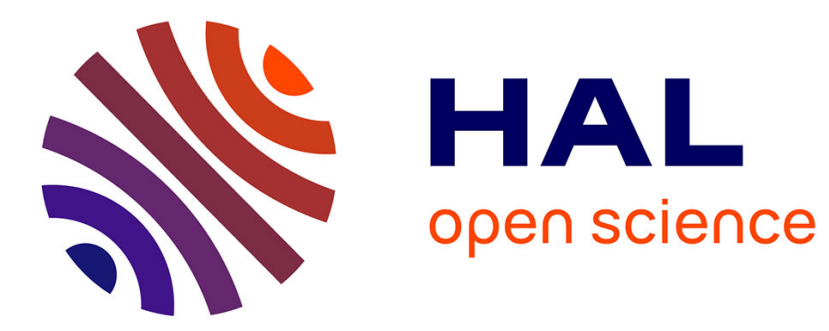

\title{
NWC Transmitter Effects on the Nightside Upper Ionosphere Observed by a Low-Altitude Satellite
} F. Němec, J. Pekař, Michel Parrot

\section{To cite this version:}

F. Němec, J. Pekař, Michel Parrot. NWC Transmitter Effects on the Nightside Upper Ionosphere Observed by a Low-Altitude Satellite. Journal of Geophysical Research Space Physics, 2020, 125 (12), pp.e2020JA028660. 10.1029/2020JA028660 . insu-03040803

\section{HAL Id: insu-03040803 https://hal-insu.archives-ouvertes.fr/insu-03040803}

Submitted on 4 Dec 2020

HAL is a multi-disciplinary open access archive for the deposit and dissemination of scientific research documents, whether they are published or not. The documents may come from teaching and research institutions in France or abroad, or from public or private research centers.
L'archive ouverte pluridisciplinaire HAL, est destinée au dépôt et à la diffusion de documents scientifiques de niveau recherche, publiés ou non, émanant des établissements d'enseignement et de recherche français ou étrangers, des laboratoires publics ou privés. 


\section{NWC Transmitter Effects on the Nightside Upper Ionosphere Observed by a Low-Altitude Satellite \\ F. Němec ${ }^{1}$, J. Pekař ${ }^{1}$, M. Parrot ${ }^{2}$ \\ ${ }^{1}$ Faculty of Mathematics and Physics, Charles University, Prague, Czech Republic}

${ }^{2}$ LPC2E/CNRS, Orléans, France

\section{Key points:}

- The NWC transmitter was not operating during a specific time period, which allows to directly its effects on the upper ionosphere.

日 Nightside ionospheric density and temperature fluctuations close to the transmitter are significantly enhanced when it is on.

- Wave intensity is increased in a large frequency range, lightning generated whistlers contribute to the increase.

Abstract

NWC is an extremely powerful very low frequency $(19.8 \mathrm{kHz})$ transmitter located in the northwest Australia. Although the transmitter typically operates continuously, it was off during the second half of 2007. This allows for a direct comparison of an ionospheric situation at the times when the transmitter is on with the times when the transmitter is off. We use electromagnetic wave and plasma measurements performed by the Detection of ElectroMagnetic Emissions Transmitted from Earthquake Regions (DEMETER) spacecraft at an altitude of about $660 \mathrm{~km}$. Given that the transmitter signal is significantly attenuated in lower ionospheric layers during the daytime and, moreover, the dayside ionosphere is controlled primarily by the solar radiation, concealing possible transmitter-related effects, we focus exclusively on the nightside. We show that although the NWC transmitter signal does not significantly change the mean plasma density and only slightly increases the electron temperature, it causes significant perturbations of both these quantities at distances up to about $200 \mathrm{~km}$. The wave intensity is considerably enhanced in the same spatial region close to the transmitter in a large range of frequencies above about $14 \mathrm{kHz}$. Finally, clear signatures of transmitter induced electron precipitation are detected to the east of the transmitter at somewhat larger L-shells, consistent with a gyroresonance condition.

\section{Introduction}

The NWC transmitter located at North West Cape, Australia $\left(21.82^{\circ} \mathrm{S}, 114.17^{\circ} \mathrm{E}\right)$ operates at $19.8 \mathrm{kHz}$. With a transmission power of about $1 \mathrm{MW}$ it is the most powerful transmission station in the Southern hemisphere (note that as the transmitter is a military device, its exact transmission power remains secret; it seems that during specific time intervals it did not reach the maximum levels although the transmitter was operating). Similarly to other very low frequency (VLF) transmitters operating at frequencies between about 10 and $30 \mathrm{kHz}$, it is used by military for a long range communication with submarines. The generated signals can propagate considerable distances in the waveguide formed between the Earth's surface and the bottom of the ionosphere with very little attenuation (Budden, 1961). However, a part of the wave power escapes the waveguide to the near-Earth space plasma environment.

Corresponding author: František Němecfrantisek.nemec@mff.cuni.cz

This article has been accepted for publication and undergone full peer review but has not been through the copyediting, typesetting, pagination and proofreading process, which may lead to differences between this version and the Version of Record. Please cite this article as doi: 10.1029/2020JA028660. 
Such signals get considerably attenuated when penetrating through lower ionospheric layers (Cohen et al., 2012), but they ultimately make it to higher altitudes. This can be readily experimentally demonstrated by increased wave intensities at respective transmitter signal frequencies measured by low-altitude spacecraft above the transmitter locations and close to the magnetically conjugate regions (Cohen \& Inan, 2012; X. Zhang et al., 2017; Zhao et al., 2019) as well as at larger radial distances (Foster et al., 2016; Ma et al., 2017; Koronczay et al., 2018). The signal propagation appears to be primarily unducted (Z. Zhang et al., 2018), in particular at lower L-shells (Clilverd et al., 2008). Although these two ways of propagation need not to result in significantly different spatial distributions of wave power, they result in strikingly different wave normal angles along the propagation paths (Starks et al., 2020), which in turn affect the precipitation of energetic electrons induced by these signals (Rodger et al., 2010; Albert et al., 2020).

Effects stemming from the propagation of powerful VLF transmitter signals in the near-Earth space are expected to occur primarily on the nightside, where the signal attenuation in the ionosphere is lower (Graf et al., 2013) and the resulting wave intensities penetrating to the space are larger (Meredith et al., 2019). The transmitter signal results in an ionospheric heating and perturbations, both over a given VLF transmitter location and - at least in some cases - also in the magnetically conjugated region (Bell et al., 2011). These can, in turn, cause an easier penetration of VLF to medium frequency (MF, $300 \mathrm{kHz}$ to 3 $\mathrm{MHz}$ ) waves through the ionosphere (Lefeuvre et al., 2013), resulting in identifiable increases of longterm average MF power spectral densities measured by low altitude spacecraft close to the transmitter locations (Parrot et al., 2009). The ionospheric heating was further shown to affect subionospheric propagation paths (Graf et al., 2011). Moreover, the related ionospheric perturbations may result in a spectral broadening of VLF transmitter emissions (Xia et al., 2020) for sufficiently strong transmitter signals (Mishin et al., 2010). If several transmitters operate at not too distant locations, new emissions may be eventually formed by wave-wave interactions (Němec et al., 2017).

Another significant effect of VLF transmitter emissions, taking place in the equatorial region at larger radial distances, is the transmitter induced precipitation of radiation belt electrons (Sauvaud et al., 2008). Drift-loss cone electron fluxes at energies of a few hundred $\mathrm{keV}$ in a given range of L-shells were shown to increase by 2-3 orders of magnitude due to the NWC transmitter operation (Gamble et al., 2008; Li et al., 2012). The precipitating energies as a function of L-shell can be described by a gyroresonant condition (Cunningham et al., 2020) and the flux increases are detected primarily to the east of the transmitter due to the electron azimuthal drift (Z. Zhang et al., 2016). A theoretical analysis of precipitation signatures produced by VLF transmitters reveals that the NWC transmitter induces the strongest signature due to its optimal location, low operating frequency, and high radiated power (Kulkarni et al., 2008). Models of VLF transmitter effects on radiation belt electrons were eventually developed, demonstrating the transmitter importance at least in specific radial distances and energy ranges (Selesnick et al., 2013; Ma et al., 2017; Ross et al., 2019).

In the present paper, we use the fact that the NWC transmitter was off for a considerable amount of time in 2007. This allows us to directly experimentally evaluate its effects on the wave intensity, plasma density, electron temperature, and precipitating electron fluxes by comparing the values measured at the times when the transmitter was operating with those when it was not. We further use the fact that the NWC transmitter in spring 2010 was keying rather than operating continuously, which allows us to investigate related short term (on the order of seconds) variations of the wave intensity. Data measured by the low-altitude Detection of Electromagnetic Emissions Transmitted from Earthquake Regions (DEMETER) spacecraft between 2006 and 2010 are used for this purpose. The spacecraft measurements are described in section 2. The results obtained are presented in section 3 and they are discussed in section 4. Finally, the main results are briefly summarized in section 5 .

\section{Data}

DEMETER was a low-altitude French spacecraft operating between 2004 and 2010 on a circular polar orbit. The initial altitude of about $710 \mathrm{~km}$ was decreased to about $660 \mathrm{~km}$ in December, 2005. The orbit

This article is protected by copyright. All rights reserved. 
was Sun-synchronous, so that principally all measurements were performed in two distinct local times, either close to 10:30 (hereinafter referred to as "day") or close to 22:30 hours (hereinafter referred to as "night"). The spacecraft measured continuously at geomagnetic latitudes lower than about 65 degrees. It operated in two different modes, termed "Burst" and "Survey". During the Burst mode, which was active only during specific time intervals, data with higher resolution were measured. In the frequency range of interest (up to $20 \mathrm{kHz}$ ), waveform of a single magnetic (Parrot et al., 2006) and a single electric (Berthelier, Godefroy, Leblanc, Malingre, et al., 2006) field component was measured with a sampling frequency of $40 \mathrm{kHz}$ and digitized with a 16 bit resolution. A low-pass filtering was applied before the data sampling. The frequency response of the filter was flat up to $17.4 \mathrm{kHz}$, with the slope at higher frequencies of about $-12 \mathrm{~dB} /$ octave. Not only the NWC transmitter signal at $19.8 \mathrm{kHz}$, but also strong signals with frequencies higher than the Nyquist frequency $(20 \mathrm{kHz})$ can be thus detected due to aliasing. Due to a significant number of interferences in the magnetic field data, only the electric field data are used in the present study. The dynamic range of the electric field instrument is $85 \mathrm{~dB}$. In the Survey mode, the available data consist of onboard calculated frequency-time spectrogram of power spectral density of electric field fluctuations with a frequency resolution of about $19.53 \mathrm{~Hz}$ (1024 frequency bins between 0 and $20 \mathrm{kHz}$ ) and a time resolution of about $2 \mathrm{~s}$. In the Burst mode, the measured electric field waveform is available, allowing for variable frequency and time resolutions based on a used spectral analysis method. Langmuir probe on board the satellite provided measurements of plasma number density and electron temperature with a $1 \mathrm{~s}$ resolution irrespective of the satellite mode (Lebreton et al., 2006). Energetic electron fluxes close to the loss cone were measured in 128 (256) energy channels between about $70 \mathrm{keV}$ and $2.3 \mathrm{MeV}$ with a time resolution of $4 \mathrm{~s}(1 \mathrm{~s})$ in the Survey (Burst) mode (Sauvaud et al., 2006).

\section{Results}

Figure 1. Average power spectral density of electric field fluctuations at a frequency of $19.8 \mathrm{kHz}$ around the NWC transmitter location is color coded according to the color scale on the right-hand side. The nighttime data obtained during the entire duration of the DEMETER mission are used. The distances are calculated between the spacecraft location and the transmitter location projected along the magnetic field line to the spacecraft altitude $(660 \mathrm{~km})$. The field-aligned projection of the transmitter location is shown by the black square symbol in the middle. The vertical projection of the transmitter location is shown by the black cross toward the south.

Average power spectral density of electric field fluctuations at frequencies around $19.8 \mathrm{kHz}$ close the NWC transmitter location is color coded in Figure 1 according to the color scale on the right-hand side. The Survey mode nighttime data obtained during the entire DEMETER mission are used to construct the plot. The power spectral densities are averaged over three frequency bins (about $60 \mathrm{~Hz}$ ) around the transmitter signal frequency and the spatial resolution is $25 \mathrm{~km}$ both in geographic east-west (abscissa) and north-south (ordinate) directions. The distances are calculated between the spacecraft location and the transmitter location projected along the magnetic field line to the spacecraft altitude $(660 \mathrm{~km})$. The intensity peak related to the transmitter operation is clearly visible. It is well centered around the middle of the plot marked by the black square, corresponding to a field-aligned signal propagation in the ionosphere. Should the signal propagate vertically up from the transmitter location, the intensity peak would be expected to occur around the black cross located about $400 \mathrm{~km}$ (i.e., about 3.6 latitudinal degrees) southward. The apparent stripes in the plot correspond to individual spacecraft orbits (which are, during the nighttime, oriented from south-east to north-west). Finally, a hint of the signal interference pattern due to its propagation in the Earth-ionosphere waveguide can be seen in the bottom part of the plot.

Figure 2. Power spectral density of electric field fluctuations at a frequency of $19.8 \mathrm{kHz}$ as a function of the distance between the spacecraft and the field line projection of the transmitter. The red vertical line marks the limit of $200 \mathrm{~km}$ used in the further analysis.

This article is protected by copyright. All rights reserved. 
Figure 2 shows the measured average power spectral density as a function of the distance between the spacecraft location and the transmitter location projected along the ambient magnetic field to the spacecraft altitude $(660 \mathrm{~km})$. A power spectral density peak at the lowest distances, with the intensity gradually decreasing with increasing distance, is clearly seen. Looking at Figure 1, the slight displacement of the peak power from zero distance can be attributed to the aforementioned stripes of individual orbits and a randomness stemming from low amount of data acquired at the lowest distances. However, selecting spacecraft locations with field-aligned projections within $200 \mathrm{~km}$ from the transmitter (marked by the red vertical line) allows for a convenient selection of locations where the detected transmitter wave power is the most significant. We note that although the exact choice of this distance threshold is clearly somewhat arbitrary, it has only minor effects on the results presented below in Figure 3. We adopt a value which corresponds to the spatial extent of most significant ionospheric changes related to the transmitter operation demonstrated hereinafter.

Figure 3. (a) Time dependence of power spectral density of electric field fluctuations at a frequency of $19.8 \mathrm{kHz}$ at distances within $200 \mathrm{~km}$ from the transmitter. The horizontal lines at the top mark the time intervals (July-December) considered in the further analysis. The transmitter was on during the four time intervals marked by red and it was off during the single time interval marked by blue. Power spectral density of electric field fluctuations at a frequency of $19.8 \mathrm{kHz}$ at distances within $200 \mathrm{~km}$ from the transmitter as a function of in-situ measured electron density. Only the data measured during the four time intervals marked by the red bars in panel (a) were used. The red line corresponds to the best power law fit.

Power spectral density of electric field fluctuations at the transmitter signal frequency measured at distances within $200 \mathrm{~km}$ from the transmitter is analyzed in Figure 3a as a function of time. Each data point plotted represents a single power spectral density measured close to the transmitter. It can be seen that while the measured power spectral densities in the proximity of the transmitter are most of the time rather high, there are three distinct time intervals when the measured power spectral densities are by about six orders of magnitude lower. These are the time intervals when the NWC transmitter is off and only normal transmitter non-related background electromagnetic waves are detected (the first and the second interval) or the transmitter is not operating continuously, but it is rather keying (the third interval). In the following analysis, we aim to compare the ionospheric situation at the times when the transmitter is on and at the times when it is off. Considering possible seasonal dependence of the situation, it is desirable to compare the measurements performed during same the parts of the year. Moreover, the somewhat higher DEMETER spacecraft altitude during the beginning of the mission might also affect the wave intensities and plasma parameters measured. We thus limit the analysis only to data measured in years 2006-2010. Moreover, considering that the longest transmitter off period occurred in July-December 2007 (beginning slightly sooner and ending a bit later), we further use the data measured in July-December during the five respective years, corresponding to the time intervals marked by horizontal color lines in Figure 3a. The NWC transmitter was on in July-December 2006, 2008, 2009, and 2010 (red color lines), while it was off in July-December 2007 (blue color line).

Having identified the time intervals when the NWC was operating, we further investigate the transmitter signal intensity ( $I)$ as a function of the in-situ measured electron density $(n)$ in Figure $3 b$. Only the data measured within $200 \mathrm{~km}$ from the transmitter field line projection to the spacecraft altitude during the four time intervals when the transmitter was operating and are used. It can be seen that the measured power spectral densities are generally lower at the times of higher electron densities (Spearman's rank correlation coefficient about -0.38 ). The red line corresponds to the best power law fit, $I \square n^{-1.22}$.

Figure 4. Example data measured in the vicinity of the NWC transmitter on 21 October 2006 at the time when it was continuously operating. (a) Frequency-time spectrogram of power spectral density of electric field fluctuations measured in the Survey mode. (b) Frequency-time spectrogram of power

This article is protected by copyright. All rights reserved. 
spectral density of electric field fluctuations measured in the Burst mode. (c) Time dependence of plasma density. (d) Time dependence of electron temperature. (e) Distance of the satellite from the transmitter field line projection. (f) Zoomed Burst mode frequency-time spectrogram of power spectral density of electric field fluctuations measured in the transmitter very vicinity.

An example of variations of electromagnetic wave intensity, plasma density, and electron temperature measured in the vicinity of the transmitter during its operation is shown in Figure 4. The data were measured on 21 October 2006 between about 14:57:55 and 14:59:07 UT. The Burst mode was active during this specific time interval, allowing for the evaluation of wave power spectral density with a high time resolution. Frequency-time spectrograms of power spectral density of electric field fluctuations obtained using the Survey mode data and using the Burst mode data are plotted in Figures $4 \mathrm{a}$ and $4 \mathrm{~b}$, respectively. The frequency resolution used in the Burst mode plot is $78.125 \mathrm{~Hz}$ and the time resolution is $0.0128 \mathrm{~s}$. The frequency range between 10 and $20 \mathrm{kHz}$ is plotted, with the NWC transmitter signal $(19.8 \mathrm{kHz})$ corresponding to the intense horizontal line identifiable at the very top. Additionally, significantly increased wave intensities spanning (with decreasing intensities) as low as about $12 \mathrm{kHz}$ are seen in the large portion of the plots around the middle of the plotted time interval, corresponding to the closest proximity to the transmitter. These appear not to be continuous in time, but rather formed by distinct short-lasting waves spanning over a large range of frequencies, suggestive of a possible relation to lightning generated whistlers. Moreover, this apparent discreteness provides a supporting piece of evidence that the observed signals are indeed real and not an instrumental artifact due to the extremely large NWC signal intensity detected. Finally, we note that although the frequency resolution of DEMETER measurements above $20 \mathrm{kHz}$ is as low as $3.255 \mathrm{kHz}$, it allows to identify increased wave intensities in this time interval up to about $25 \mathrm{kHz}$ (not shown).

Plasma density and electron temperature plotted in Figures $4 \mathrm{c}$ and $4 \mathrm{~d}$ exhibit significant fluctuations during this specific time interval, albeit their mean values remain quite unchanged. Figure $4 \mathrm{e}$ shows a time dependence of the distance between the satellite and the field line projection of the transmitter location to the spacecraft altitude, demonstrating that the observed variations of wave intensity and plasma parameters occur at the times of the closest approach to the transmitter. Finally, Figure $4 \mathrm{f}$ shows a zoomed view of Figure $4 \mathrm{~b}$ around the time of the closest approach. The frequency resolution of the plot is $156.25 \mathrm{~Hz}$ and the time resolution is $0.0032 \mathrm{~s}$. The apparent discrete structure of the emissions is still observable, but the emissions themselves do not seem to consist of distinct lightning generated whistlers. Note that the local lower hybrid frequency evaluated using the measured plasma composition (Berthelier, Godefroy, Leblanc, Seran, et al., 2006; Vavilov et al., 2013) for this particular event is about $9 \mathrm{kHz}$, i.e., below the plotted frequency range.

Figure 5. Frequency-distance plots of average power spectral density of electric field fluctuations close to the transmitter. (a) Time interval when the NWC transmitter was off. (b) Time intervals when the NWC transmitter was on.

Having demonstrated wave intensity and plasma variations close to the transmitter location in a single example event, we aim to investigate these in a more systematic way in Figures 5, 6, and 7. Figure 5 shows frequency-distance plots of average power spectral densities of electric field fluctuations close to the transmitter. Figure 5a is obtained using the Survey mode data measured during July-December 2007, when the transmitter was off. Figure $5 \mathrm{~b}$ is obtained using the Survey mode data measured during JulyDecember 2006, 2008, 2009, and 2010, when the transmitter was on. A striking difference between the two plots can be immediately seen. Not only the intense and spectrally broadened NWC transmitter signal at the top part of the plot is seen in Figure 5b as compared to Figure 5a, but also the wave intensities in a broad range of frequencies above about $14 \mathrm{kHz}$ and distances up to about $200 \mathrm{~km}$ from the transmitter location are significantly larger. The average lower hybrid frequency in the transmitter vicinity calculated over the analyzed periods is about $11 \mathrm{kHz}$, i.e., the intensity increase is observed at frequencies above the

This article is protected by copyright. All rights reserved. 
lower hybrid. Note that the large average power spectral density in the lowest distance bin in 2007 (Figure 5a) is due to a lack of data, as there are only two short time intervals when DEMETER approached so close to the transmitter in 2007) and intense lightning generated whistlers which occurred at those particular times. Also note that intense horizontal lines observable in Figure 5 at frequencies away from $19.8 \mathrm{kHz}$ are due to the operation of other VLF transmitters than NWC.

Figure 6. Plasma density variations as a function of the distance from the transmitter (abscissa) and year (ordinate) are color coded according to the color scale on the right-hand side. Only the data measured between July and December are used. (a) Mean plasma density. (b) Standard deviation of plasma density.

Plasma densities measured by DEMETER close to the NWC transmitter are analyzed in Figure 6 as a function of the distance between the spacecraft and the transmitter field line projection (abscissa) and year (ordinate). Only the data measured between July and December are used to construct the figure. Figure 6a shows average plasma density values color coded according to the color scale on the right-hand side. It can be seen that these typically range between about $1.4 \times 10^{4} \mathrm{~cm}^{-3}$ and $1.8 \times 10^{4} \mathrm{~cm}^{-3}$. The densities apparently tend to increase toward larger distances from the transmitter. This can be understood realizing that while the low distance bins are based strictly on the data measured close to the transmitter, the densities at high distance bins are based on a combination of data measured toward the north and toward south. Considering that the plasma density increases non-linearly toward lower latitudes (He et al., 2010), this may eventually result in the observed increase of densities at higher distance bins. A striking feature observed in Figure 6a are the lower densities observed in July-December 2008 (and to some extent also in July-December 2009). This can be, however, likely related to the solar minimum occurring that time. All in all, although the observed distance and year-to-year variability of plasma densities is quite significant, there appears to be no significant change of densities observed in 2007, which might be related to the non-operation of the NWC transmitter.

The situation changes considerably in Figure $6 \mathrm{~b}$, which deals with standard deviations of plasma densities in individual bins rather than with their average values. Note that the standard deviations might be expected to increase toward higher distances as, again, the data measured to the north and to the south of the transmitter are combined in there. On the other hand, the standard deviations at low distance bins are calculated from the data measured over rather short time intervals, and they are thus expected to be lower. This is roughly the case for the year 2007, when the NWC transmitter was off. However, at other years, the situation is strikingly different. The standard deviations of the plasma density are generally higher and, moreover, they seem to exhibit a local maximum at distances within about $200 \mathrm{~km}$ from the transmitter. Although the number of data at the very close distance bins is necessarily low (and there are no data at all in the lowest distance bin in 2006), the analysis performed independently for each year provides us with a rough estimate of the overall variability. Given this, it can be clearly seen that the year 2007 stands out considerably, with the standard deviations of plasma densities being about 2-3 times lower than during other years at distances up to about $200 \mathrm{~km}$ from the transmitter location.

Figure 7. Electron temperature variations as a function of the distance from the transmitter (abscissa) and year (ordinate) are color coded according to the color scale on the right-hand side. Only the data measured between July and December are used. (a) Mean electron temperature. (b) Standard deviation of electron temperature.

Figure 7 uses the same format as Figure 6 to analyze the variations of electron temperature measured by DEMETER. The arguments about the mean temperature and its standard deviation variability with distance and year are mostly the same as in the case of plasma number density. Looking at Figure 7a, one can identify somewhat lower electron temperatures in July-December 2009. Although these are again possibly attributable to the solar minimum, it remains unclear why the temperatures are not so much decreased also in July-December 2008, in line with the density decrease from Figure 6a. Another feature identifiable in Figure $7 \mathrm{a}$ is a trend of the temperature to decrease with increasing distance from the transmitter, possibly attributable to a non-linear latitudinal dependence of the temperature (He et al.,

This article is protected by copyright. All rights reserved. 
2010) and the aforementioned north-south averaging. However, the most striking feature in Figure 7a are the low electron temperatures measured in July-December 2007, i.e., during the period when the NWC transmitter was off.

We note that the statistical results presented in Figures 5, 6, and 7 are well consistent with the example shown in Figure 4. Specifically, although the average plasma density is basically unaffected and the average electron temperature only slightly increases due to the transmitter operation, their standard deviations (i.e., the fluctuation levels) increase significantly. Moreover, the wave intensity in a broad frequency range is significantly increased over basically the same region, i.e., within some $200 \mathrm{~km}$ from the transmitter.

Figure 8: Measured fluxes of precipitating electrons are color coded according to the color scale on the right-hand side. Only the data between July and December are used. (a) - (c) Precipitating electron fluxes at energies of about $100 \mathrm{keV}, 200 \mathrm{keV}$, and $250 \mathrm{keV}$, respectively, measured during the year 2007 when the NWC transmitter was off. (d) - (f) Precipitating electron fluxes at energies of about $100 \mathrm{keV}, 200$ $\mathrm{keV}$, and $250 \mathrm{keV}$, respectively, measured during the years 2006, 2008, 2009, and 2010 when then the NWC transmitter was on. The nearly horizontal dashed curves mark the field line projections of equatorial locations where a gyroresonant interaction between the transmitter signal and electrons of a given energy is expected to occur.

Having demonstrated the transmitter effects on the electromagnetic wave intensity and cold plasma properties, we finally focus on the transmitter effects on the energetic electron precipitation. Considering that the transmitter induced electron precipitation is expected not to be centered around the transmitter, but rather shifted to the east due to the eastward drift of energetic electrons trapped in the Earth's magnetic field, we use the representation as a function of the east/west and north/south distance from the transmitter rather than the total distance. The results obtained are shown in Figure 8. Figures 8a-c are obtained for July-December 2007 when the NWC transmitter was off. The individual panels correspond to different electron energies, increasing left to right $(100 \mathrm{keV}, 200 \mathrm{keV}$, and $250 \mathrm{keV}$, respectively). The nearly horizontal dashed curves mark the field line projections of equatorial locations where a gyroresonant interaction between the transmitter signal and electrons of a given energy is expected to occur. These are calculated using a plasmaspheric density model by Denton et al. (2004), assuming that the relevant wave-particle interactions take place in the equatorial plane, the transmitter signal propagates along the ambient magnetic field and the precipitated electrons are originally on the edge of the loss cone. No significant pattern can be seen, except of the precipitating electron fluxes gradually increasing toward the south of the transmitter, i.e., toward larger geomagnetic latitudes (L-shells). Moreover, the precipitating fluxes at higher energies are clearly lower than the fluxes at lower frequencies, corresponding to the electron distribution function generally decreasing with increasing energy. Figures 8d-f are obtained for July-December of 2006, 2008, 2009, and 2010, when the NWC transmitter was on. Apart from the gradual flux increase toward south (larger L-shells), a new striking feature emerges southeast of the transmitter, corresponding to the transmitter induced electron precipitation. The flux increase is the largest at lowest analyzed electron energies, and it becomes weaker at higher energies, along with lower background energetic electron fluxes at higher energies. Moreover, it is noticeable that the band of increased precipitating electron fluxes moves slightly northward (i.e., toward lower L-shells) with increasing energy. This can be well understood in terms of a gyroresonance condition, as is demonstrated by the agreement with the nearly horizontal dashed curves.

Figure 9. Example data measured in the vicinity of the NWC transmitter on 14 May 2010 at the time when it was keying. (a) Frequency-time spectrogram of power spectral density of electric field fluctuations measured in the Burst mode. (b) Time dependence of plasma density. (c) Time dependence of electron temperature. (d) Distance of the satellite from the transmitter field line projection.

In spring 2010, the NWC transmitter was not operating continuously, but it was rather keying, i.e., short intense regularly repeated signal pulses were transmitted. This mode is of a particular interest, as it

This article is protected by copyright. All rights reserved. 
allows to evaluate how the wave intensity and plasma parameters changes at the time of the pulses as compared to the surrounding time intervals on time scales of seconds. An example of the DEMETER data obtained close to the transmitter during such a period is shown in Figure 9. The format of the figure is similar to the format of Figure 4. Figure 9a shows a high-resolution frequency-time spectrogram of the power spectral density of electric field fluctuations based on the Burst mode data. The frequency and time resolution is the same as in Figure $4 \mathrm{~b}$, i.e., $78.125 \mathrm{~Hz}$ and $0.0128 \mathrm{~s}$, respectively. The times of the NWC transmitter pulses can be readily seen at the highest frequencies of the plot, following a regular temporal pattern. Moreover, particularly in the middle part of the plot when the spacecraft was very close to the transmitter field line projection, the wave intensities at the times of the pulses are enhanced over a large frequency range, being noticeable at frequencies as low as about $10 \mathrm{kHz}$. Additionally, a comparatively weaker intensity increase continuous in time is observable during the same time interval at frequencies between about 16 and $18 \mathrm{kHz}$. Electron density and temperature measurements shown in Figures $9 \mathrm{a}$ and $9 \mathrm{~b}$ reveal a noticeable density decrease, temperature increase, and considerable fluctuations during this time interval. Although the most striking intensity increases are thus strictly related to the transmitter operation, ceasing basically just after the transmitter pulses, considerable wave intensities still persist in between the pulses, over the entire region where the plasma properties are affected by the transmitter operation. The time dependence of the spacecraft distance from the transmitter field line projection in Figure $9 \mathrm{~d}$ confirms that this interval indeed corresponds to the closest approach to the transmitter.

\section{Discussion}

NWC is among the most powerful VLF transmitters worldwide, affecting ultimately the ionosphere around its location. Moreover, its occasional turn off represents a unique possibility to experimentally evaluate its effects by comparing the situation during the times when it was operating with the situation when it was not. DEMETER spacecraft is optimally suited for such an analysis, as it provides long-term continuous measurements of the space environment at low altitudes and is equipped by a comprehensive set of instruments to analyze not only the wave intensity, but also the plasma density and electron temperature, as well as precipitating energetic electron fluxes. Moreover, given its nearly Sunsynchronous orbit, the analysis is principally unaffected by intrinsic diurnal variations. Considering that the daytime ionosphere is primarily controlled by the solar radiation which introduces a significant transmitter unrelated variability and, moreover, considering that during the daytime the VLF transmitter signal gets significantly attenuated in the lower ionospheric layers inaccessible to DEMETER measurements (Cohen et al., 2012), we limit the performed analysis to the nightside.

Even on the nightside, the ionospheric properties are to a significant degree controlled by the solar activity, exhibiting both a seasonal dependence and longer term variations attributable to the solar cycle. In order to eliminate the seasonal dependence, we use the fact that DEMETER measurements were basically continuous and regularly sampling the transmitter proximity, i.e., using averages over the same periods of the year should effectively suppress possible seasonal dependences. The same is mostly true for specific solar events. Although these may possibly disturb the nightside ionosphere for short periods of time, the used averages over (at least) half a year should effectively average these out. Suppressing the solar cycle dependence is more complicated, and we principally did not make any attempt to do so. Instead, we opt to analyze the plasma density and electron temperature separately for individual years, which provides us with an estimate of the year-to-year variability. This is - at least in some cases clearly much lower than the variations related to the NWC transmitter operation.

Average plasma number density measured at the DEMETER altitude (about $660 \mathrm{~km}$ ) in the transmitter vicinity is principally unaffected by the transmitter operation, being controlled rather by the solar cycle and other transmitter unrelated variations. However, the detected transmitter signal intensity is generally lower at the times of larger in-situ measured plasma number densities. Average electron temperature seems to be slightly lower in 2007, when the transmitter was off, than during the other years. However,

This article is protected by copyright. All rights reserved. 
the most striking effect of the transmitter operation are the inhomogeneities of the two parameters expressed by their standard deviations calculated over $25 \mathrm{~km}$ distance bins. These were significantly lower in 2007, when the transmitter was off, than during any of the remaining years. Moreover, the effect is found to be well localized around the transmitter, to distances within about $200 \mathrm{~km}$. This result is in agreement with a case study by Parrot et al. (2007), suggesting that the significant transmitter power escaping to the space above the transmitter induces ionospheric variations at that given location. Given a single point nature of the available measurements, it is not possible to experimentally distinguish whether these variations are temporal or whether they are rather formed by short-scale localized structures. It is, however, noteworthy that they are not localized vertically above the transmitter but rather around the respective field line projection to the satellite altitudes. This can be explained by the transmitter signal propagation in the ionosphere principally along the ambient magnetic field rather than vertically (Cohen \& Inan, 2012).

The wave intensity in the transmitter vicinity is necessarily increased at the transmitter frequency (19.8 $\mathrm{kHz}$ ). However, the wave intensity increase extends down to much lower frequencies, being clearly observable at frequencies as low as about $14 \mathrm{kHz}$. This can be explained by the transmitter signal broadening due to the scattering at induced ionospheric irregularities (Bell et al., 2008; Galinsky et al., 2011) once a critical threshold NWC signal amplitude is reached (Xia et al., 2020). However, given the apparently discrete nature of the emissions in the respective range of frequencies identifiable in the Burst mode data, it appears that lightning generated whistlers scattered on these irregularities might possibly also contribute to the observed emissions (Baker et al., 2000). The events when the NWC transmitter was keying rather than operating continuously can provide more insight into this phenomenon. At the times of the NWC transmitter pulses the situation is principally the same as at the times of the transmitter continuous operation. However, the plasma irregularities induced by its operation do not disappear after the transmitter pulse, and the plasma environment in the transmitter vicinity thus remains favorable for the wave scattering even during the short time intervals between the transmitter pulses. Consequently, the wave intensity is found to be increased not only during the transmitter pulses themselves, but also albeit considerably less - in between them. During these times, however, the wave intensity increase is not attributable to the transmitter spectral broadening, but rather to the scattering of lightning generated whistlers.

\section{Conclusions}

The turn off of the NWC transmitter in July-December 2007 allows for a direct evaluation of its effects on wave and plasma parameters measured by the low-altitude DEMETER spacecraft in the upper ionosphere. We compare the wave intensity, plasma density, and electron temperature measured in JulyDecember 2007 when the transmitter was off with those measured during the same months of other years (2006, 2008, 2009, and 2010), when the transmitter was on. It turns out that the observed effects are not centered around the transmitter location, but they are rather shifted northward, corresponding to a roughly field-aligned transmitter signal propagation in the ionosphere. Average plasma density is nearly unaffected by the transmitter operation and average electron temperature increases only slightly as a result of the transmitter operation within about $200 \mathrm{~km}$ from the transmitter field line projection. On the other hand, significant perturbations of both the plasma density and electron temperature are observed at the times of the transmitter operation. The measured wave intensity in this spatial region is increased not only at frequencies corresponding to the transmitter signal itself, but principally in the entire frequency range above about $14 \mathrm{kHz}$. Based on the burst-like structure identifiable in the high resolution wave data, we suggest that this intensity increase might be possibly at least partly related to lightning generated emissions scattered at the transmitter induced plasma irregularities. This is further supported by the fact that, during the transmitter keying, the wave intensity is increased (albeit significantly less) also in between the transmitter pulses, principally over the entire spatial region where significant plasma perturbations are observed. Finally, we demonstrate that the transmitter induced electron precipitation is

This article is protected by copyright. All rights reserved. 
easily discernible to the south-east of the transmitter, corresponding to the eastward azimuthal drift of electrons trapped in the Earth's magnetic field and the cyclotron resonance condition.

\section{Acknowledgments}

We thank the engineers from CNES and scientific laboratories (CBK, IRAP, LPC2E, LPP, and SSD of ESTEC) who largely contributed to the success of the DEMETER mission. DEMETER data are accessible from the https://sipad-cdpp.cnes.fr website. F. N. and J. P. acknowledge the support of GACR Grant 18-00844S.

References

Albert, J. M., Starks, M. J., Selesnick, R. S., Ling, A. G., O’Malley, S., \& Quinn, R. A. (2020). VLF transmitters and lightning-generated whistlers: 2. diffusion of radiation belt electrons. J. Geophys. Res. Space Physics, 125(e2019JA027030). doi: 10.1029/2019JA027030

Baker, S. D., Kelley, M. C., Swenson, C. M., Bonnell, J., \& Hahn, D. V. (2000). Generation of electrostatic emissions by lightning-induced whistler-mode radiation above thunderstorms. J. Atm. Solar-Terr. Phys., 62, 1393-1404. doi: 10.1016/S1364-6826(00)00127-9

Bell, T. F., Graf, K., Inan, U. S., Piddyachiy, D., \& Parrot, M. (2011). DEMETER observations of ionospheric heating by powerful VLF transmitters. Geophys. Res. Lett., 38(L11103). doi: 10.1029/2011GL047503

Bell, T. F., Inan, U. S., Piddyachiy, D., Kulkarni, P., \& Parrot, M. (2008). Effects of plasma density irregularities on the pitch angle scattering of radiation belt electrons by signals from ground based VLF transmitters. Geophys. Res. Lett., 35(L19103). doi: 10.1029/2008GL034834

Berthelier, J. J., Godefroy, M., Leblanc, F., Malingre, M., Menvielle, M., Lagoutte, D., ... Pfaff, R. (2006). ICE, the electric field experiment on DEMETER. Planet. Space Sci., 54, 456471. doi: 10.1016/j.pss.2005.10.016

Berthelier, J. J., Godefroy, M., Leblanc, F., Seran, E., Peschard, D., Gilbert, P., \& Artru, J. (2006). IAP, the thermal plasma analyzer on DEMETER. Planet. Space Sci., 54, 487-501. doi: 10.1016/j.pss.2005.10.018

Budden, K. G. (1961). The wave-guide mode theory of wave propagation. London, Great Britain: Logos Press.

Clilverd, M. A., Rodger, C. J., Gamble, R., Meredith, N. P., Parrot, M., Berthelier, J.-J., \& Thomson, N. R. (2008). Ground-based transmitter signals observed from space: Ducted or nonducted? J. Geophys. Res., 113(A04211). doi: 10.1029/2007JA012602

Cohen, M. B., \& Inan, U. S. (2012). Terrestrial VLF transmitter injection into the magnetosphere. J. Geophys. Res., 117(A08310). doi: 10.1029/2012JA017992

Cohen, M. B., Lehtinen, N. G., \& Inan, U. S. (2012). Models of ionospheric VLF absorption of powerful ground based transmitters. Geophys. Res. Lett., 39(L24101). doi: 10.1029/2012GL054437

This article is protected by copyright. All rights reserved. 
Cunningham, G. S., Botek, E., Perrard, V., Cully, C., \& Ripoll, J.-F. (2020). Observation of high-energy electrons precipitated by NWC transmitter from PROBA-V low-earth orbit satellite. Geophys. Res. Lett.(e2020GL089077). doi: 10.1029/2020GL089077

Denton, R. E., Manietti, J. D., Goldstein, J., Young, S. L., \& Anderson, R. R. (2004). Electron density in the magnetosphere. J. Geophys. Res., 109(A09215). doi: 10.1029/2003JA010245

Foster, J. C., Ericksson, P. J., Baker, D. N., Jaynes, A. N., Mishin, E. V., Fennel, J. F., ... Kanekal, S. G. (2016). Observations of the impenetrable barrier, the plasmapause, and the VLF bubble during the 17 March 2015 storm. J. Geophys. Res. Space Physics, 121, 55375548. doi: 10.1002/2016JA022509

Galinsky, V. L., Schevchenko, V. I., Mischin, E. V., \& Starks, M. J. (2011). Numerical modeling of 3D weak turbulence driven by high-power VLF pump waves in the topside ionosphere. Geophys. Res. Lett., 38(L16105). doi: 10.1029/2011GL048441

Gamble, R. J., Rodger, C. J., Clilverd, M. A., Sauvaud, J.-A., Thomson, N. R., Stewart, S. L., ... Berthelier, J.-J. (2008). Radiation belt electron precipitation by man-made VLF transmissions. J. Geophys. Res., 113(A10211). doi: 10.1029/2008JA013369

Graf, K. L., Inan, U. S., \& Spasojevic, M. (2011). Transmitter-induced modulation of subionospheric VLF signals: Ionospheric heating rather than electron precipitation. $J$. Geophys. Res., 116(A12313). doi: 10.1029/2011JA016996

Graf, K. L., Lehtinen, N. G., Spasojevic, M., Cohen, M. B., Marshall, R. A., \& Inan, U. S. (2013). Analysis of experimentally validated trans-ionospheric attenuation estimates of VLF signals. J. Geophys. Res. Space Physics, 118, 2708-2720. doi: 10.1002/jgra.50228

He, Y., Yang, D., Zhu, R., Qian, J., \& Parrot, M. (2010). Variations of electron density and temperature in the ionosphere based on the DEMETER ISL data. Earthq. Sci., 23, 349-355. doi: 10.1007/s11589-010-0732-8

Koronczay, D., Lichtenberger, J., Juhász, L., Steinbach, P., \& Hospodarsky, G. (2018). VLF transmitters as tools for monitoring the plasmasphere. J. Geophys. Res. Space Physics, 123, 9312-9324. doi: 10.1029/2018JA025802

Kulkarni, P., Inan, U. S., Bell, T. F., \& Bortnik, J. (2008). Precipitation signatures of groundbased VLF transmitters. J. Geophys. Res., 113(A07214). doi: 10.1029/2007JA012569

Lebreton, J.-P., Stverak, S., Travnicek, P., Maksimovic, M., Klinge, D., Merikallio, S., ... Salaquarda, M. (2006). The ISL Langmuir probe experiment processing onboard DEMETER: Scientific objectives, description and first results. Planet. Space Sci., 54, 472486. doi: 10.1016/j.pss.2005.10.017

Lefeuvre, F., Pinçon, J. L., \& Parrot, M. (2013). Midlatitude propagation of VLF to MF waves through nighttime ionosphere above powerful VLF transmitters. J. Geophys. Res. Space Physics, 118, 1210-1219. doi: 10.1002/jgra.50177

Li, X., Ma, Y., Wang, P., Wang, H., Lu, W., Zhang, X., ... Parrot, M. (2012). Study of the North West Cape electron belts observed by DEMETER satellite. J. Geophys. Res., 117(A04201). doi: 10.1029/2011JA017121

This article is protected by copyright. All rights reserved. 
Ma, Q., Mourenas, D., Li, W., Artemyev, A., \& Thorne, R. M. (2017). VLF waves from groundbased transmitters observed by the Van Allen Probes: Statistical model and effects on plasmaspheric electrons. Geophys. Res. Lett., 44, 6483-6491. doi: 10.1002/2017GL073885

Meredith, N. P., Horne, R. B., Clilverd, M., \& Ross, J. P. J. (2019). An investigation of VLF transmitter wave power in the inner radiation belt and slot region. J. Geophys. Res. Space Physics, 124, 5246-5259. doi: 10.1029/2019JA026715

Mishin, E. V., Starks, M. J., Ginet, G. P., \& Quinn, R. A. (2010). Nonlinear VLF effects in the topside ionosphere. Geophys. Res. Lett., 37(L04101). doi: 10.1029/2009GL042010

Němec, F., Čížek, K., Parrot, M., Santolík, O., \& Záhlava, J. (2017). Line radiation events induced by very low frequency transmitters observed by the DEMETER spacecraft. $J$. Geophys. Res. Space Physics, 122, 7226-7239. doi: 10.1002/2017JA024007

Parrot, M., Benoist, D., Berthelier, J. J., Blecki, J., Chapuis, Y., Colin, F., ... Zamora, P. (2006). The magnetic field experiment IMSC and its data processing onboard DEMETER: Scientific objectives, description and first results. Planet. Space Sci., 54, 441-455. doi: 10.1016/j.pss.2005.10.015

Parrot, M., Inan, U. S., Lehtinen, N. G., \& Pinçon, J. L. (2009). Penetration of lightning MF signals to the upper ionosphere over VLF ground-based transmitters. J. Geophys. Res., 114(A12318). doi: 10.1029/2009JA014598

Parrot, M., Sauvaud, J. A., Berthelier, J. J., \& Lebreton, J. P. (2007). First in-situ observations of strong ionospheric perturbations generated by a powerful VLF ground-based transmitter. Geophys. Res. Lett., 34(L11111). doi: 10.1029/2007GL029368

Rodger, C. J., Carson, B. R., Cummer, S. A., Gamble, R. J., Clilverd, M. A., Green, J. C., ... Parrot, M. (2010). Contrasting the efficiency of radiation belt losses caused by ducted and nonducted whistler-mode waves from ground-based transmitters. J. Geophys. Res., 105(A12208). doi: 10.1029/2010JA015880

Ross, J. P. J., Meredith, N. P., Glauert, S. A., Horne, R. B., \& Clilverd, M. A. (2019). Effects of VLF transmitter waves on the inner belt and slot region. J. Geophys. Res. Space Physics, 124, 5260-5277. doi: 10.1029/2019JA026716

Sauvaud, J.-A., Maggiolo, R., Jacquey, C., Parrot, M., Berthelier, J.-J., Gamble, R. J., \& Rodger, C. J. (2008). Radiation belt electron precipitation due to VLF transmitters: Satellite observations. Geophys. Res. Lett., 35(L09101). doi: 10.1029/2008GL033194

Sauvaud, J. A., Moreau, T., Maggiolo, R., Treilhou, J.-P., Jacquey, C., Cros, A., .. Gangloff, M. (2006). High-energy electron detection onboard DEMETER: The IDP spectrometer, description and first results on the inner belt. Planet. Space Sci., 54, 502-511. doi: 10.1016/j.pss.2005.10.019

Selesnick, R. S., Albert, J. M., \& Starks, M. J. (2013). Influence of a ground-based VLF radio transmitter on the inner electron radiation belt. J. Geophys. Res. Space Physics, 118, 628635. doi: 10.1002/jgra.50095

This article is protected by copyright. All rights reserved. 
Starks, M. J., Albert, J. M., Ling, A. G., O'Malley, S., \& Quinn, R. A. (2020). VLF transmitters and lightning-generated whistlers: 1. modeling waves from source to space. J. Geophys. Res. Space Physics, 125(e2019JA027029). doi: 10.1029/2019JA027029

Vavilov, D. I., Shklyar, D. R., Titova, E. E., \& Parrot, M. (2013). Study of the lower hybrid resonance frequency over the regions of gathering earthquakes using DEMETER data. $J$. Atm. Solar-Terr. Phys., 100-101. doi: 10.1016/j.jastp.2013.03.019

Xia, Z., Chen, L., Zhima, Z., \& Parrot, M. (2020). Spectral broadening of NWC transmitter signals in the ionosphere. Geophys. Res. Lett., 47(e2020GL088103). doi: 10.1029/2020GL088103

Zhang, X., Zhao, S. F., Ruzhin, Y., Liu, J., \& Song, R. (2017). The spatial distribution of three Alpha transmitter signals at the topside ionosphere. Radio Sci., 52, 653-662. doi: 10.1002/2016RS006219

Zhang, Z., Chen, L., Li, X., Xia, Z., Heelis, R. A., \& Horne, R. B. (2018). Observed propagation route of VLF transmitter signals in the magnetosphere. J. Geophys. Res. Space Physics, 123, 5228-5537. doi: 10.1029/2018JA025637

Zhang, Z., Li, X., Wang, C., \& Chen, L. (2016). North west cape-induced electron precipitation and theoretical simulation. Chin. Phys. B, 25(11), 119401. doi: 10.1088/1674$1056 / 25 / 11 / 119401$

Zhao, S., Zhou, C., Shen, X., \& Zhima, Z. (2019). Investigation of VLF transmitter signals in the ionosphere by ZH-1 observations and full-wave simulation. J. Geophys. Res. Space Physics, 124, 4697-4709. doi: 10.1029/2019JA026593

This article is protected by copyright. All rights reserved. 


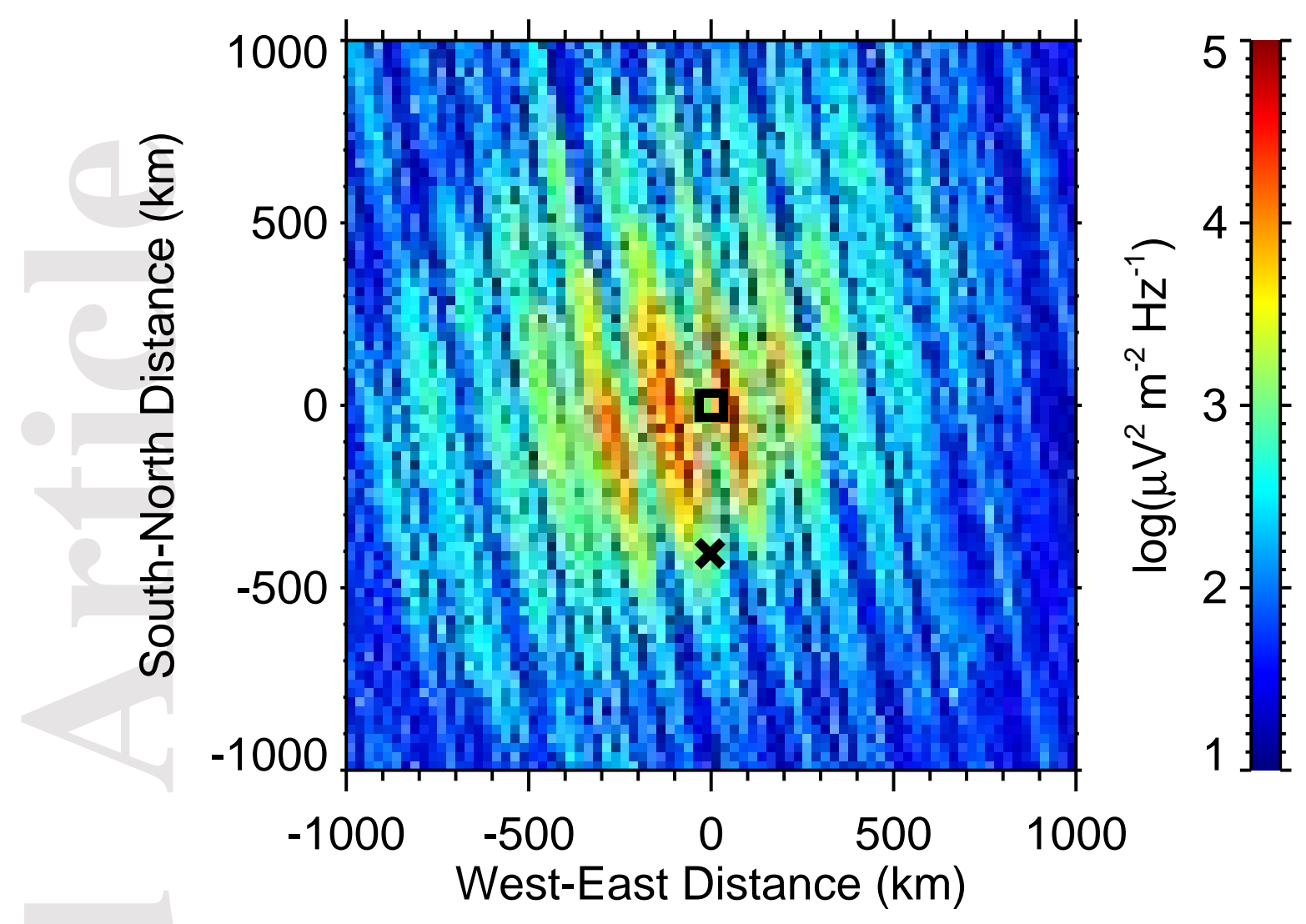

This article is protected by copyright. All rights reserved. 


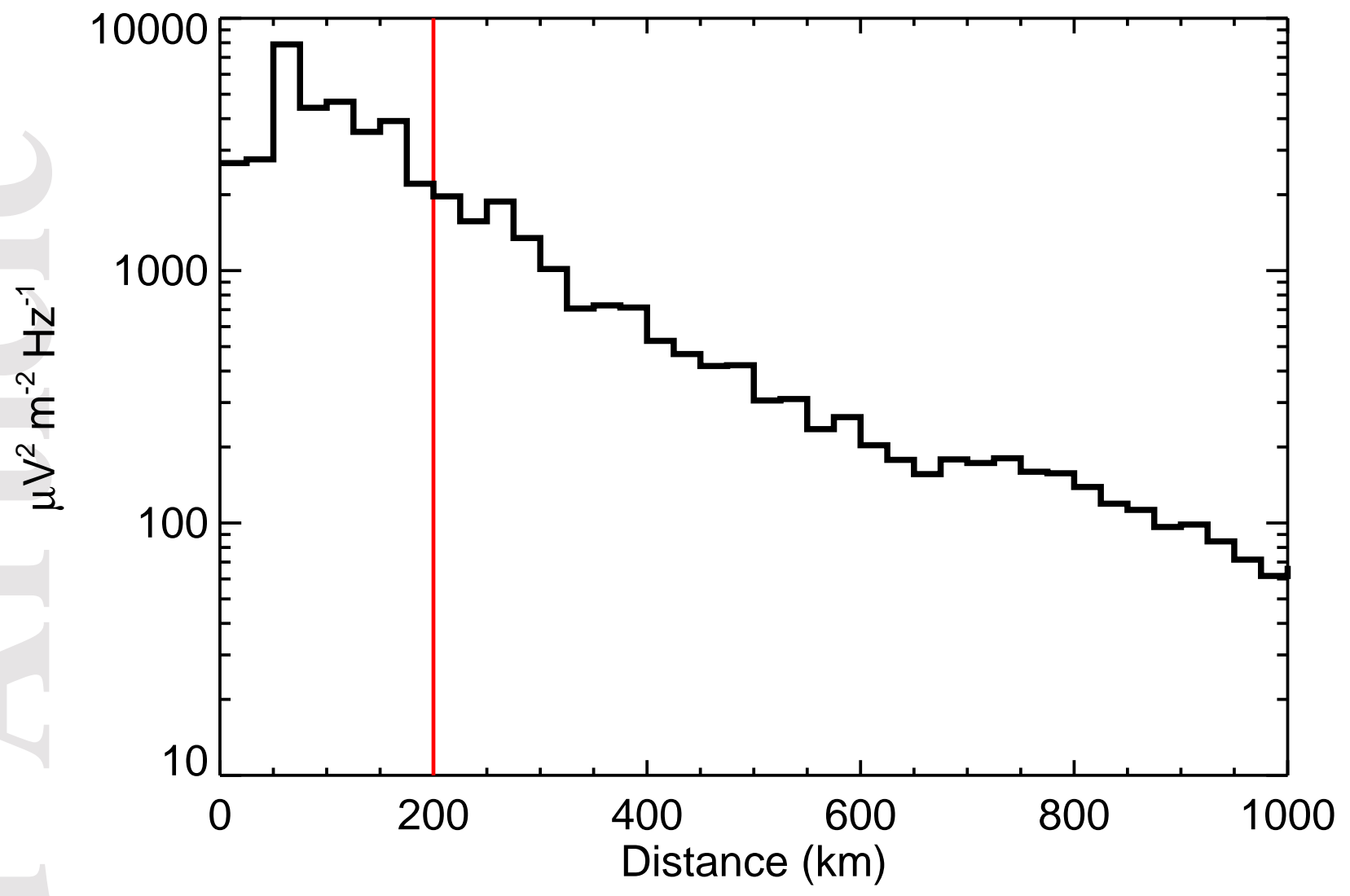

This article is protected by copyright. All rights reserved. 

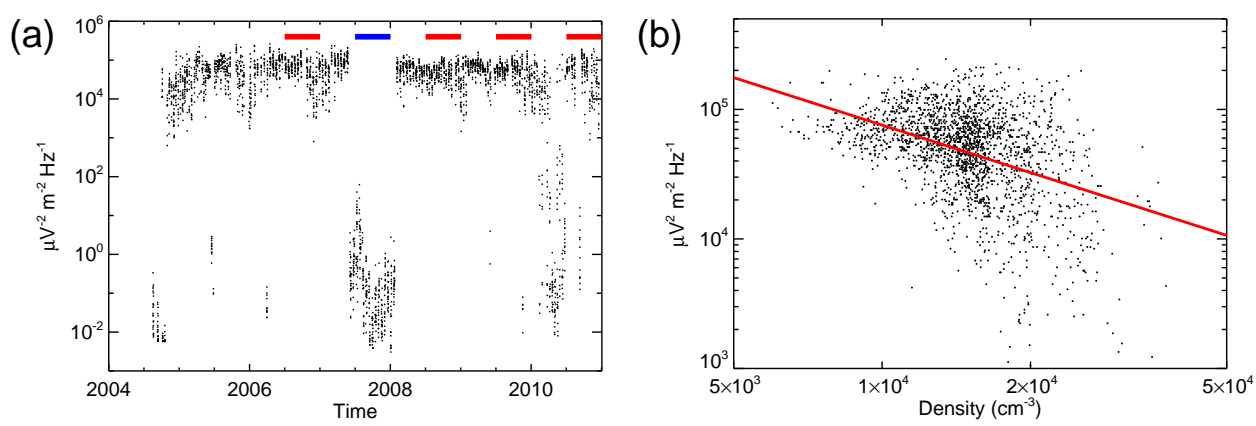

This article is protected by copyright. All rights reserved. 


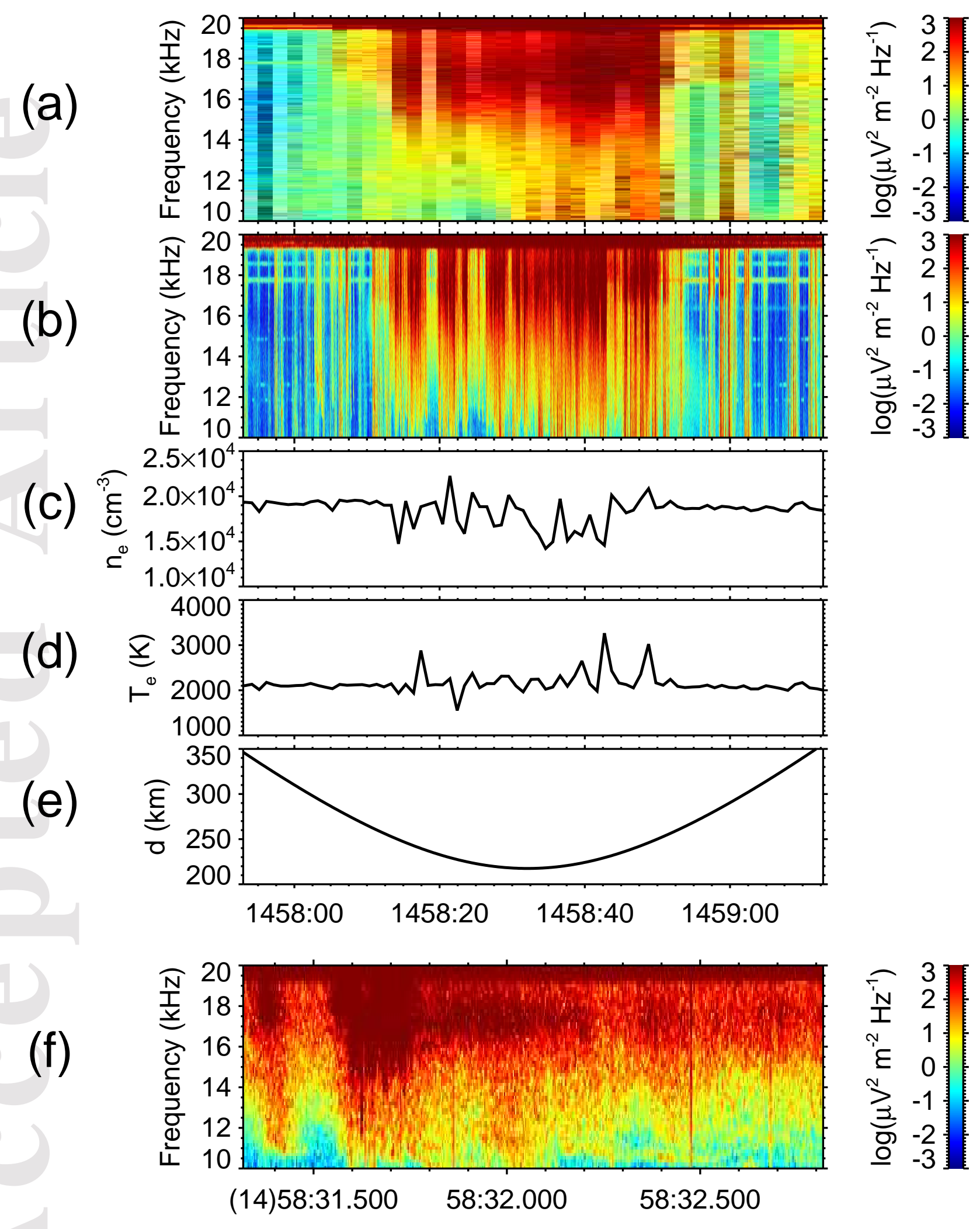

This article is protected by copyright. All rights reserved. 
(a)

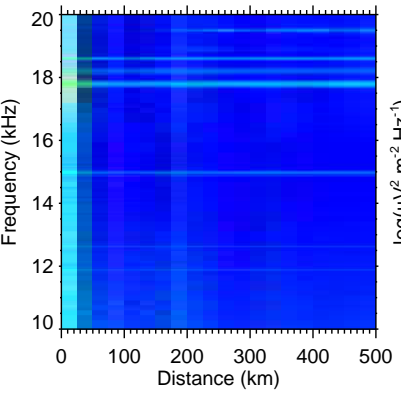

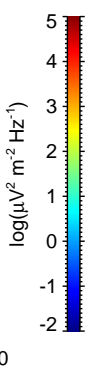

(b)

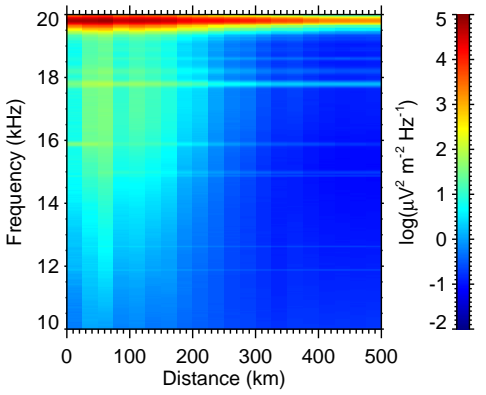

This article is protected by copyright. All rights reserved. 
(a)

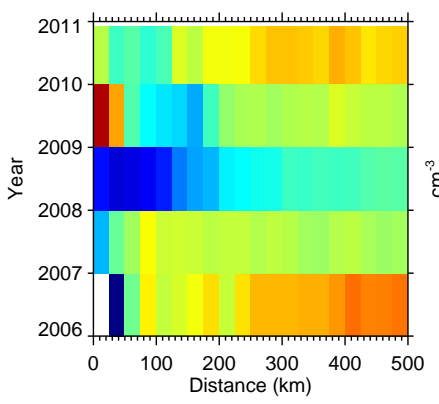

(b)

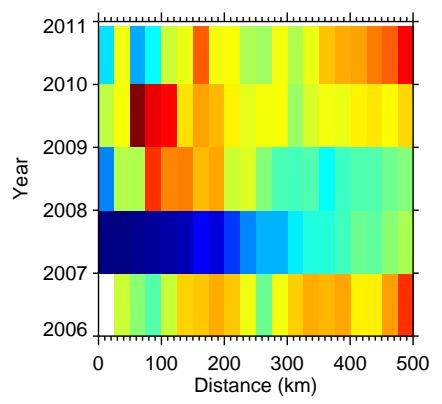

1600
1400
1200
1000
800
600
400

This article is protected by copyright. All rights reserved. 
(a)

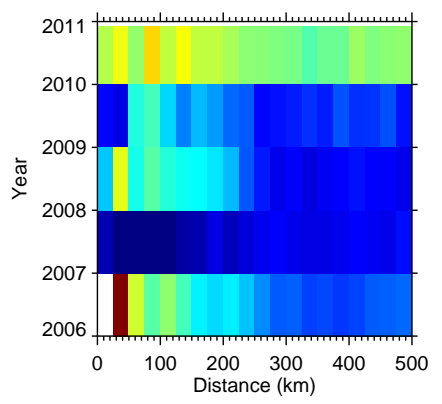

(b)

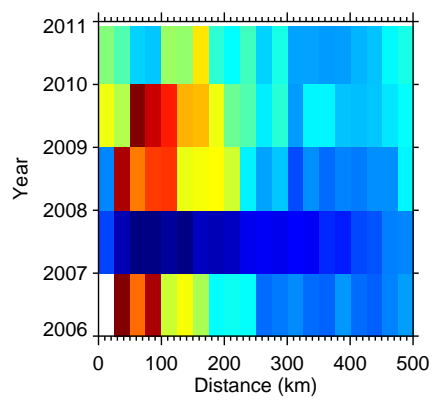

This article is protected by copyright. All rights reserved. 

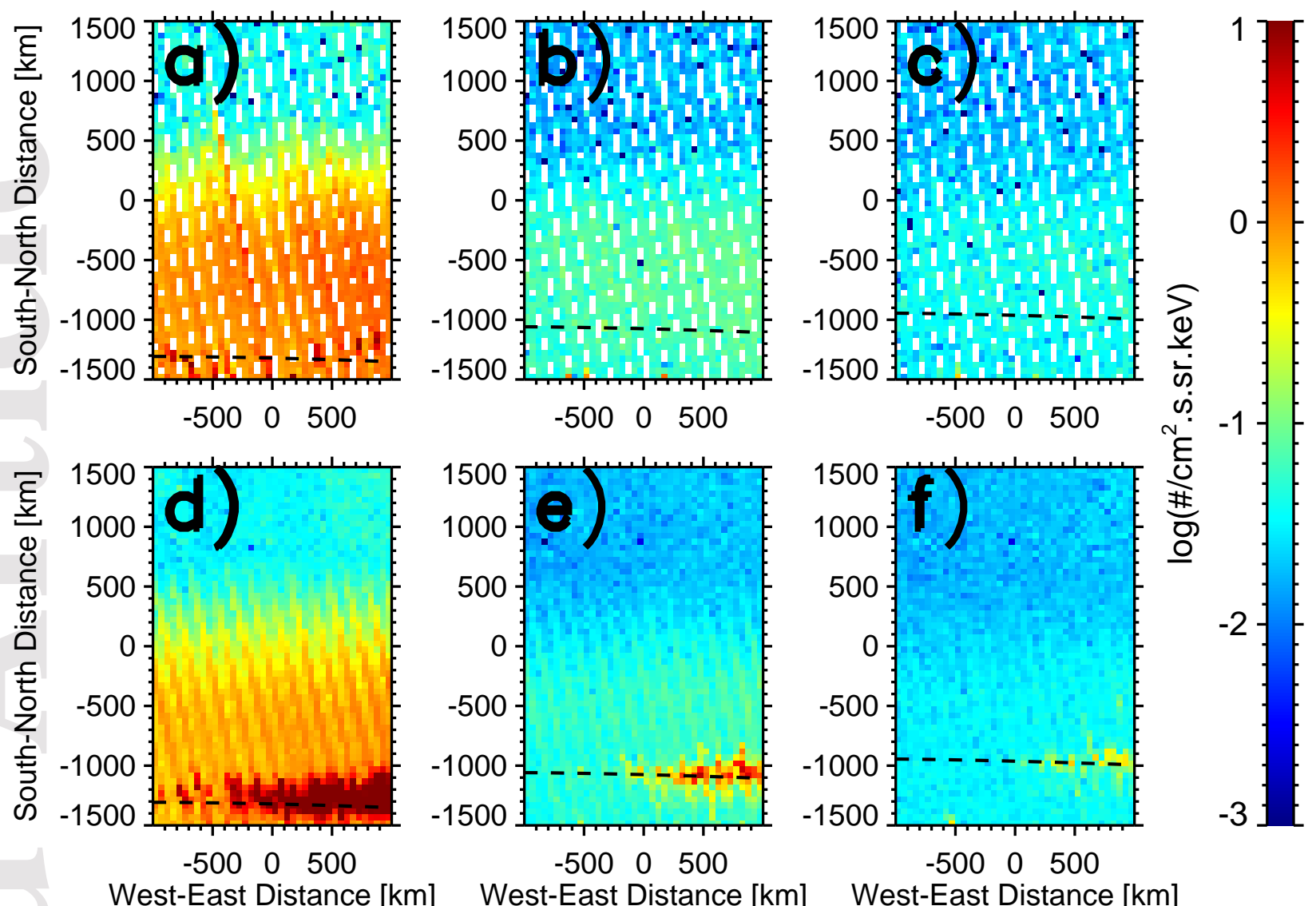

West-East Distance [km]

West-East Distance [km]

West-East Distance [km]

This article is protected by copyright. All rights reserved. 

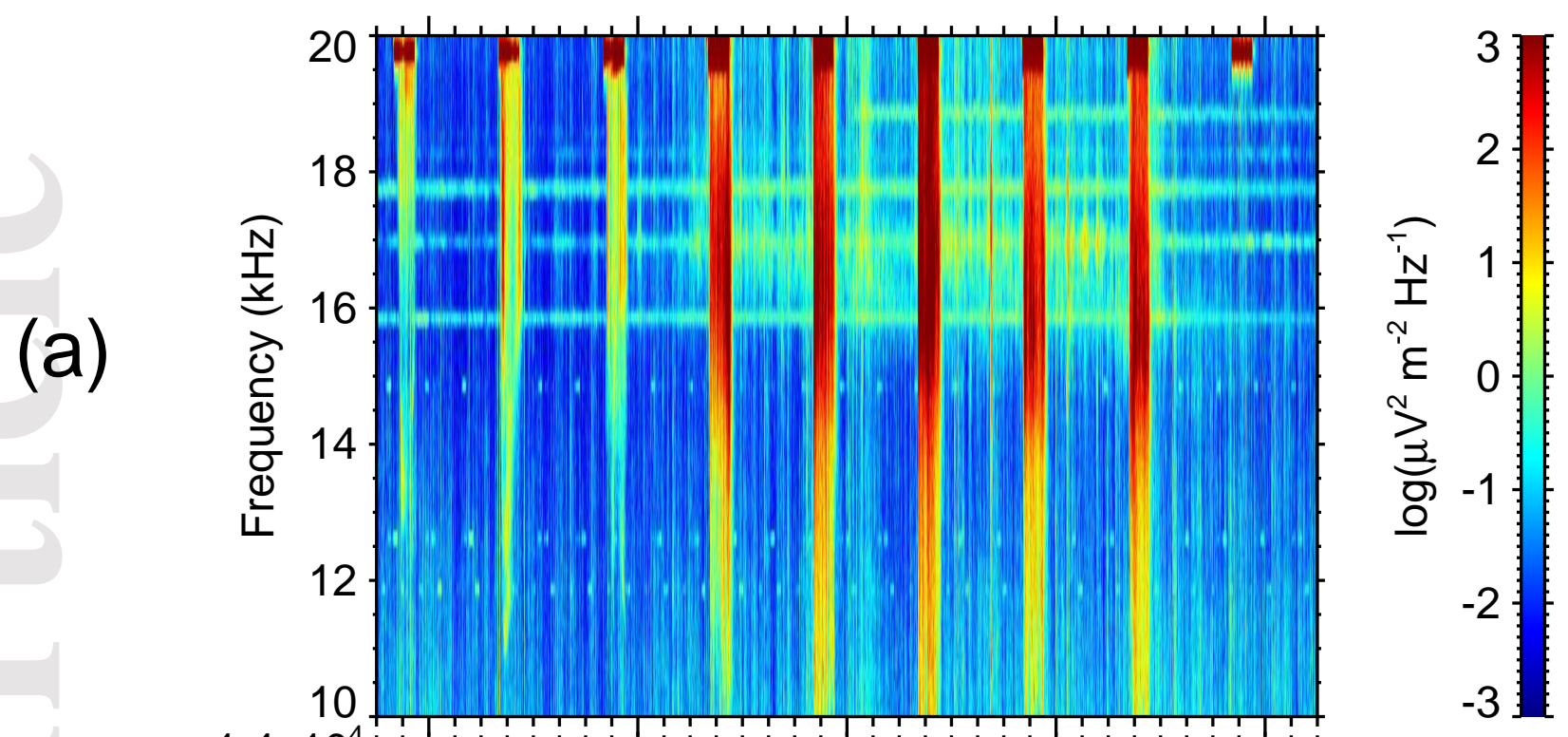

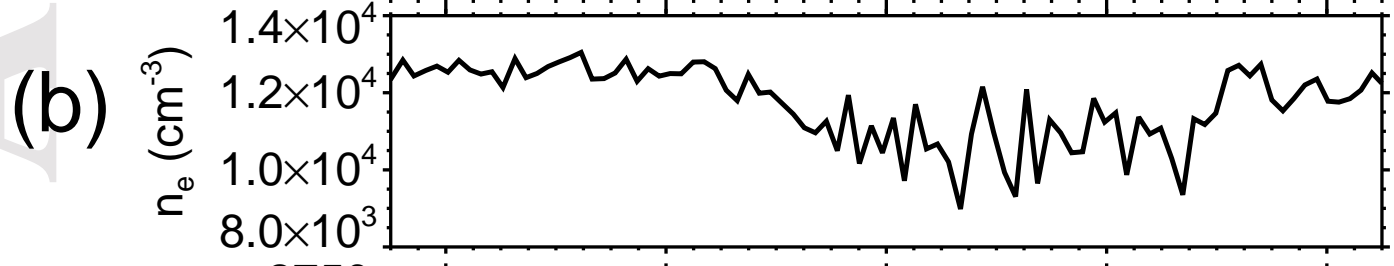

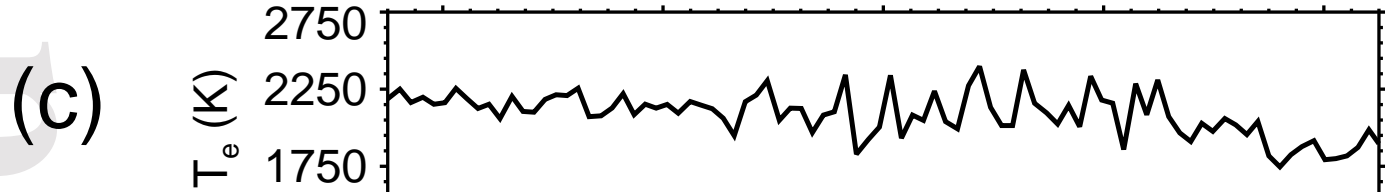

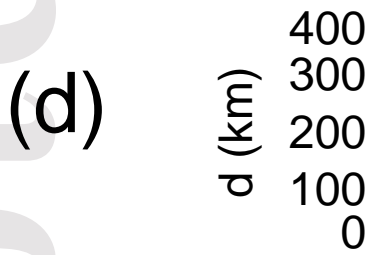

1416:20 1416:40 1417:00 1417:20 1417:40 